\title{
Multiplatform-Based Digital Market Designs as Marketing and Sales Media of MSME Products in Pleret Village
}

Perancangan Pasar Digital Berbasis Multiplatform sebagai Media Pemasaran dan Penjualan Produk UMKM Desa Pleret

\section{Taufik Kamal $^{1}$, Zulfatun Ruscitasari ${ }^{2}$, Yana Hendriana ${ }^{3}$, Wahma Ravenna Rafail ${ }^{4}$}

1,3,4 Teknik Komputer, Universitas Nahdlatul Ulama Yogyakarta, Indonesia

${ }^{2}$ Akuntansi, Universitas Nahdlatul Ulama Yogyakarta, Indonesia

1'taufiq@unu-jogja.ac.id, 22zulfatunr@unu-jogja.ac.id, ${ }^{3}$ yanahendri@unu-jogja.ac.id,

Informasi Artikel

Received: July 2021

Revised: September 2021

Accepted: October 2021

Published: October 2021

Keywords: digital market; Multiplatform; MSMEs Kata kunci: digital market; Multiplatform; MSMEs

\begin{abstract}
Purpose: Objective: This study aims to design a multiplatform-based digital market to help rural MSMEs (Micro, Small, Medium Enterprises) market and sell their products in order to increase the competitiveness of MSMEs.

Design/methodology/approach: The design of the digital platform of Ngedolke.com used a design thinking strategy.

This study used the black box method to test the functional suitability of the developed application.

Findings/result: This study produces an analysis and system design that is used to develop the digital platform of Ngedolke.com. Thus, it can be used to develop the system further.

Originality/value/state of the art: The difference between this study and previous studies lies in the use of system design of a design thinking strategy. Besides, the technology used is multiplatform-based.
\end{abstract}

Abstrak
Tujuan: Penelitian ini bertujuan untuk merancang pasar
digital berbasis Multiplatform yang diharapkan dapat
membantu UMKM desa memasarkan dan menjualkan
produknya guna meningkatkan daya saing usaha kecil,
menengah dan mikro.
Perancangan/metode/pendekatan: Perancangan platform
digital Ngedolke.com menggunakan strategi design
thinking. Dalam penelitian ini, pengujian menggunakan
metode black box untuk menguji kesesuaian fungsional
aplikasi yang dibuat.
Hasil: penelitian ini menghasilkan analisis dan perancangan
sistem yang dimanfaatkan untuk mengembangkan platform


digital ngedolke.com. Sehingga dapat dimanfaatkan untuk mengembangan sistem lebih lanjut.

Keaslian/ state of the art: Perbedaan penelitian ini dari penelitian sebelumnya yaitu pada metode perancangan sistemnya menggunakan strategi design thinking. Selain itu, teknologi yang digunakan telah berbasis multiplatform.

\section{Pendahuluan}

Kemajuan pesat teknologi informasi dalam beberapa tahun terakhir membawa implikasi pada dunia usaha. Hal tersebut dikarenakan transformasi teknologi dapat mendorong pertumbuhan ekonomi yang lebih efisien dan berdaya saing [1]. Saat ini, cara transaksi secara langsung atau tatap muka telah digantikan oleh e-commerce. Menurut [2], e-commerce memiliki lima aspek diantaranya perdagangan, kolaborasi, komunikasi, koneksi dan komputasi yang mengarahkan pada peluang inovasi. Pesatnya perkembangan e-commerce saat ini berhasil menarik perusahaan untuk menggunakan teknologi digital karena dianggap dapat membantu meningkatkan peluang bisnis dan daya saing industry [3].

Melalui era 4.0 perkembangan teknologi informasi di era pandemi Covid-19 membentuk kebiasaan baru masyarakat dalam hal proses transaksi jual beli. Di masa yang akan datang, internet akan mempunyai peran penting dalam proses transaksi bisnis [4]. Internet memungkinkan interaktivitas antara pembeli dan penjual untuk menciptakan ruang pasar bersama yang real-time [5]. Dengan adanya platform digital memungkinkan produsen dan konsumen untuk berinteraksi secara online. Platform digital diharapkan dapat memberikan banyak manfaat untuk perusahaan industry dengan adanya integrasi dengan konsep industry 4.0 [6].

Perkembangan $e$-commerce telah memberikan kesempatan bagi masyarakat di pedesaan dan perkotaan untuk menikmati aktivitas belanja online [7]. Semakin canggihnya teknologi digital saat ini, maka akses masyarakat dalam melakukan transaksi elektronik akan semakin mudah. Sejalan dengan yang dinyatakan oleh [8] dan [9] bahwa pemanfaatan teknologi $e$ commerce pada UMKM merupakan sebuah solusi untuk mengatasi kendala UMKM dalam memasarkan dan menjual produknya, karena kebanyakan UMKM menggunakan sistem pemasaran konvensional. Hal itu sejalan dengan yang disampaikan [10] bahwa teknologi $e$ commerce merupakan salah solusi bagi UKM untuk mengeluarkan produk baru dengan biaya yang sangat efektif, memasarkan bisnis, meningkatkan komunikasi, mengumpulkan informasi dan menemukan calon mitra bisnis.

Kemudahan akses teknologi informasi juga membawa dampak positif bagi dunia usaha, terutama UMKM [11]. Sebagai penopang dalam sektor Ekonomi, Usaha Mikro Kecil Menengah (UMKM) perlu senantiasa diberikan dukungan [12] dan [13]. Kebijakan Pemberlakuan Pembatasan Kegiatan Masyarakat (PPKM) mengubah kebiasaan masyarakat yang dulu gemar keluar rumah dan beraktivitas, menjadi sangat berhati - hati dengan membatasi berpergian [14]. Hal ini tentunya berimbas pada kegiatan transaksi jual beli di masyarakat. Beberapa sektor ekonomi yang terkena dampak yakni pusat perbelanjaan, pasar, transportasi, hingga UMKM, dimana salah satunya yang terdampak adalah UMKM Desa Pleret. 
Desa Pleret berada wilayah Kabupaten Bantul yang memiliki potensi ekonomi cukup tinggi. Hal tersebut dikarenakan selain terkenal dengan sektor wisatanya, Pleret juga banyak memiliki UMKM yang sangat potensial untuk dikembangkan. Misalnya, usaha di bidang otomotif, kuliner, kerajinan dan agrobisnis. Namun, di masa pandemi saat ini, usaha-usaha mereka cenderung stagnan bahkan menurun. Saat ini UMKM Desa Pleret kesulitan untuk menjual produk-produknya, karena masih banyak yang menggunakan bisnis offline. Kurangnya media pemasaran UMKM menyebabkan terjadinya penurunan penjualan produk. Hal tersebut dikarenakan UMKM Desa Pleret masih banyak yang belum menggunakan teknologi digital untuk menunjang usahanya. Padahal saat ini strategi pemasaran telah bergeser dari konvensional menjadi pemasaran digital [15].

Oleh sebab itu, diperlukan media yang dapat mempermudah UMKM memasarkan dan menjualkan produk UMKM Desa Pleret yaitu dengan menggunakan platform digital. Platform digital memungkinkan sistem berbagi di antara kelompok pengguna, menyediakan layanan digital untuk berkomunikasi dan melakukan transaksi, serta mengumpulkan, memproses, dan berbagi data yang terkait dengan minat atau aktivitas [16]. Pasar digital berbasis multiplatform merupakan bentuk upaya untuk meningkatkan rasa memiliki antar warga dengan jargonnya "tetuku marang tangga" yang berarti saling membantu sesama tetangganya dengan cara membeli produk-produk UMKM yang ada disekitarnya, dengan begitu roda perekonomian desa akan berputar. Hal ini bertujuan agar memudahkan pelaku UMKM memiliki media pemasaran produknya dan memahami penggunaan teknologi e-commerce.

\section{Metode/Perancangan}

Penelitian ini menggunakan strategi design thinking dengan memfokuskan pada pemecahan masalah dilapangan. Design thinking adalah metode yang memiliki enam tahapan yang dapat membantu mengembangkan penelitian dari fase awal hingga fase akhir, beberapa tahapannya yaitu: menganalisis dan memahami kebutuhan, mendefinisikan masalah, menggali ide, mengembangkan model atau desain, implementasi, dan menguji sampel yang representatif [17]. Sedangkan untuk mengembangkan aplikasi, menurut [18] dibutuhkan langkah-langkah sebagai berikut:

a) Mendefinisikan Kebutuhan

Tahap analisis kebutuhan adalah proses penentuan kebutuhan dasar aplikasi proyek. Tujuan dari persyaratan adalah untuk memahami bagaimana aplikasi berjalan dan bagaimana pengguna berinteraksi dengan aplikasi [19]. Penelitian diawali dengan melakukan pengumpulan, analisis dan pengolahan informasi data di lapangan yang berkaitan dengan pengembangan sistem pasar digital yang akan diimplementasikan di desa.

b) Sistem Permodelan dan Sumber Daya

Pada tahap ini dilakukan pemodelan aplikasi dan sumber daya, yang bertujuan untuk merancang dan memodelkan komponen perangkat lunak sebagai bagian dari aplikasi front-end, back-end, aplikasi mobile apps dan database.

c) Pengembangan

Pada fase ini, beberapa kegiatan yang dilakukan adalah a) pengembangan perangkat lunak, b) integrasi konten, dan c) integrasi perangkat untuk interaksi antara pengguna dan perangkat lunak yang dikembangkan. Jadi, tahap pengembangan adalah suatu 
proses penulisan kode program menggunakan bahasa pemrograman dan perangkat lunak pendukung lainnya. Proses pelaksanaan dilakukan berdasarkan spesifikasi dan kebutuhan sistem yang telah telah ditetapkan pada saat perancangan sistem. Sehingga, proses implementasi harus selesai sampai tahapan sistem siap diuji.

d) Evaluasi

Tahap evaluasi bertujuan untuk melakukan tes eksperimental untuk mengevaluasi komputasi aplikasi Pengujian merupakan elemen dasar yang menjamin kualitas dan menggambarkan desain, spesifikasi, serta pengkodean. Dalam penelitian ini, awal pengujian menggunakan metode black box untuk menguji kesesuaian fungsional aplikasi yang dibuat. Selanjutnya dilakukan implementasi di lapangan dengan mengambil beberapa vendor yang telah siap dengan produk-produk yang akan dipasarkan. Serta menguji pelanggan yang akan membeli produk dari vendor.

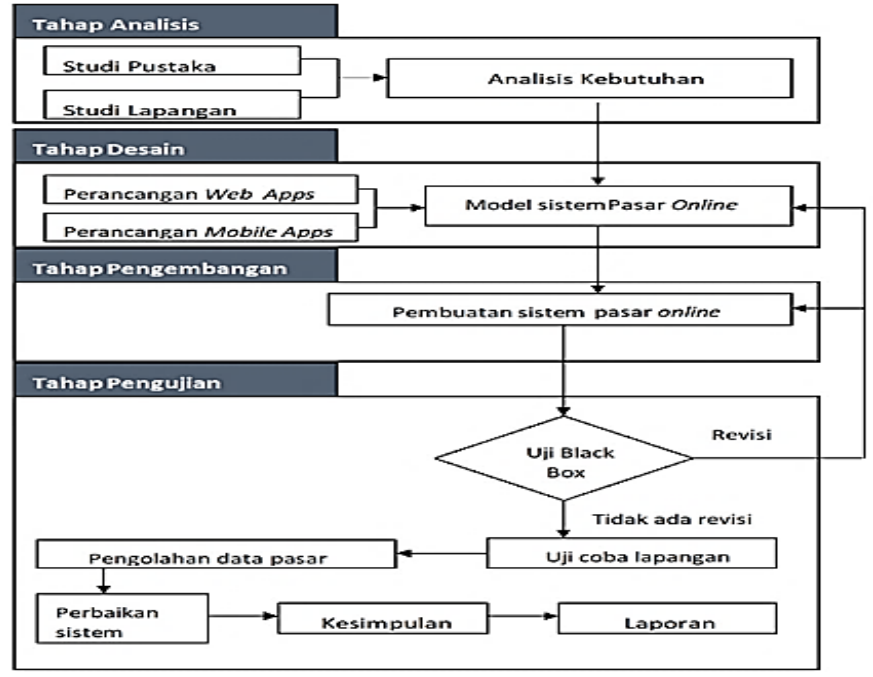

Gambar 1. Model Penelitian

\section{Hasil dan Pembahasan}

Ngedolke.com adalah sebuah teknologi e-commerce yang mempertemukan penjual dengan pembeli lewat internet. Pada dasarnya, e-commerce menyediakan wadah untuk vendor yang ingin menawarkan dagangannya di website atau mobile apps. Kemudian E-commerce akan menampilkan produk dari yang ditawarkan kepada customer atau yang sedang customer cari. Ketika customer ingin membeli barang tersebut, maka dapat membayar secara langsung melalui E-commerce atau Cash on Delivery (COD). Platform ini nantinya juga akan berbasis multivendor atau bermacam-macam vendor sehingga produk yang ditawarkan akan beraneka ragam. Teknologi E-commerce ini nantinya tidak hanya melibatkan berbagai macam vendor, tetapi juga melibatkan pemerintah desa selaku admin atau pengelola yang mengawasi dan memonitoring berjalannya sistem. Pemodelan dan desain sistem e-commerce dapat memecahkan masalah promosi dan pemasaran usaha kecil dan menengah di daerah ini [20]. 


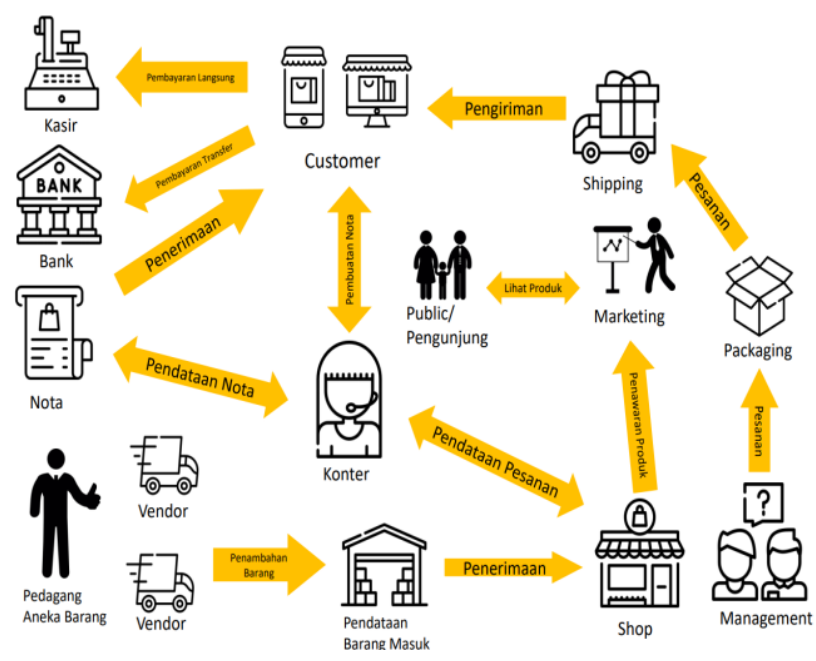

Gambar 2. Proses Berjalannya Sistem

\subsection{Use Case Diagram}

Use case diagram menerangkan tentang apa yang bisa dikerjakan sistem dilihat dari sudut pandang penngguna (user). Use case diagram berhubungan dengan skenario. Skenario adalah sebuah contoh kejadian yang terjadi ketika pengguna saling berhubungan dengan aplikasi. Actor adalah orang atau obyek yang berinteraksi dengan aplikasi. Actor merupakan pengguna aplikasi atau aplikasi lainnya yang saling berinteraksi dengan aplikasi tersebut. Berikut adalah desain use case diagram untuk sistem yang dibuat dalam penelitian ini.

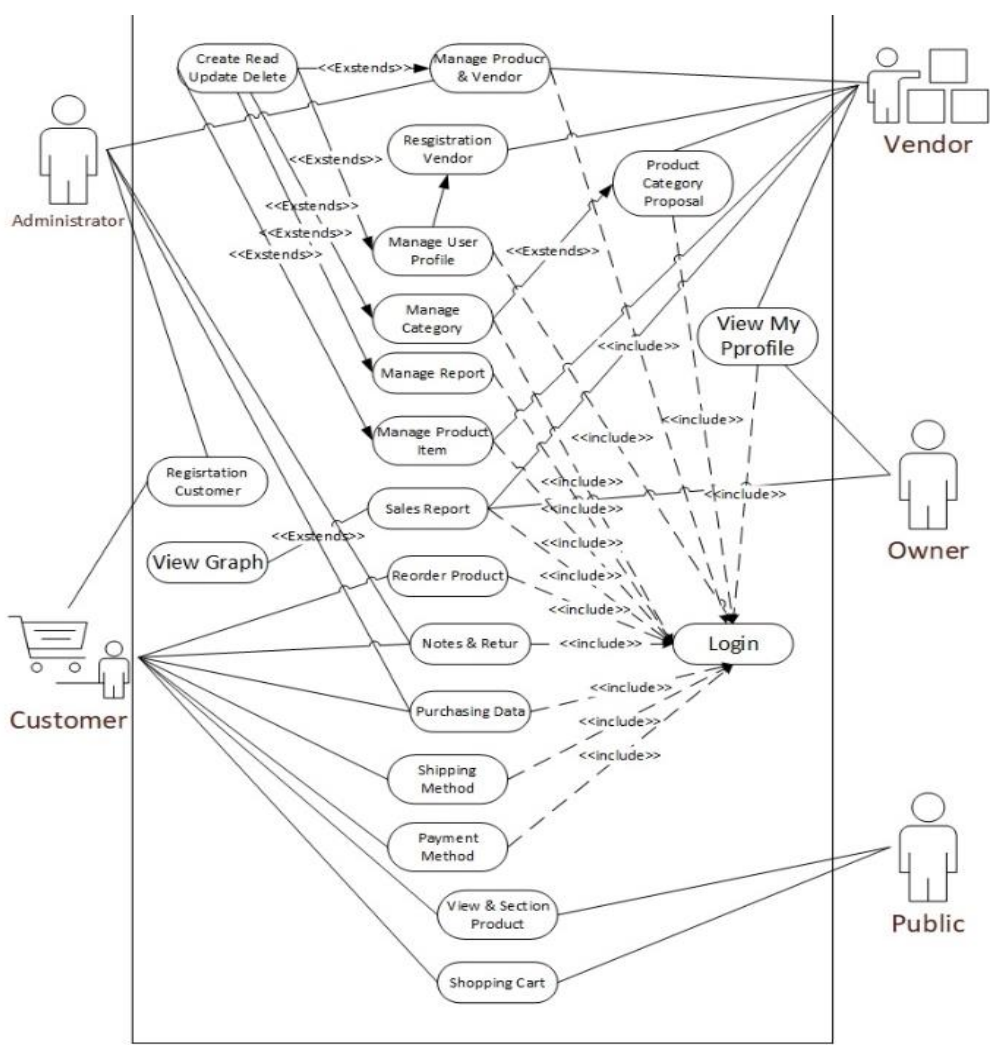

Gambar 3. Use Case Diagram Pasar Digital 


\subsection{Rancangan Basis Data}

Dalam pengembangan aplikasi diperlukan basis data untuk menyimpan data khususnya yang berhubungan dengan proses presensi. Pengembangan basis data dilakukan dengan membuat pemodelan data yang dikenal dengan nama ERD (Entity Relationship Diagram).

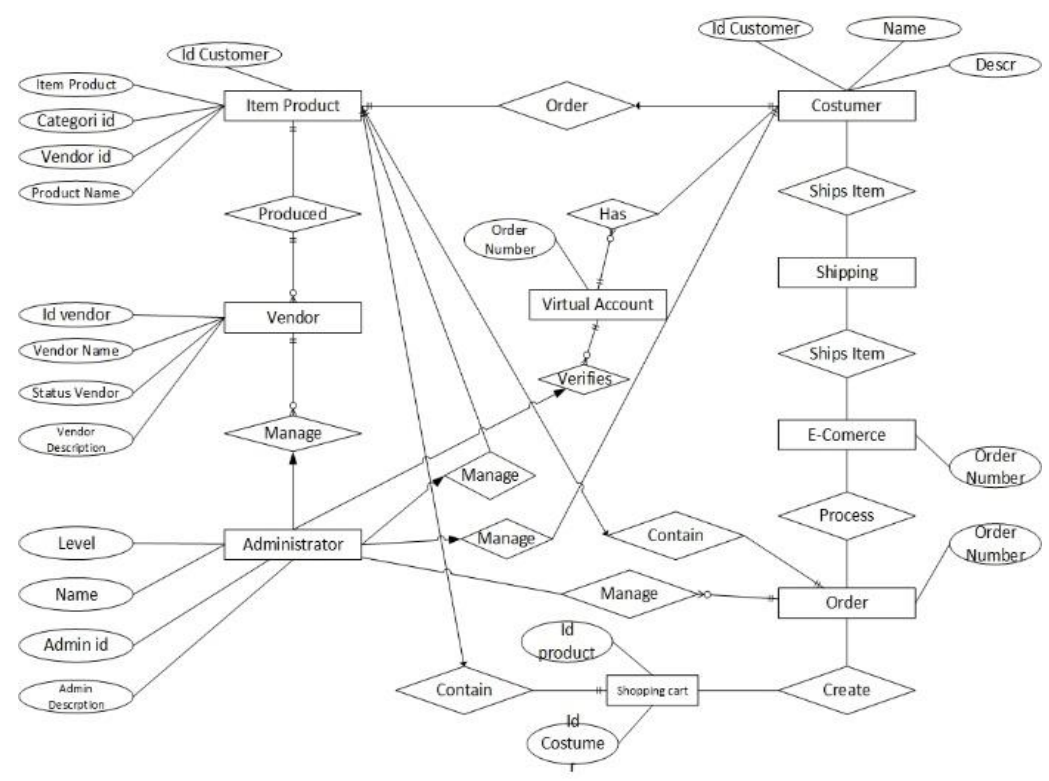

Gambar 5. ERD perancangan database Pasar Online

\subsection{Diagram Kelas}

Digram kelas berfungsi menggambarkan kumpulan dari kelas dan hubungannya. Pada Gambar 5 menunjukkan kelas yang terlibat dalam pasar digital.

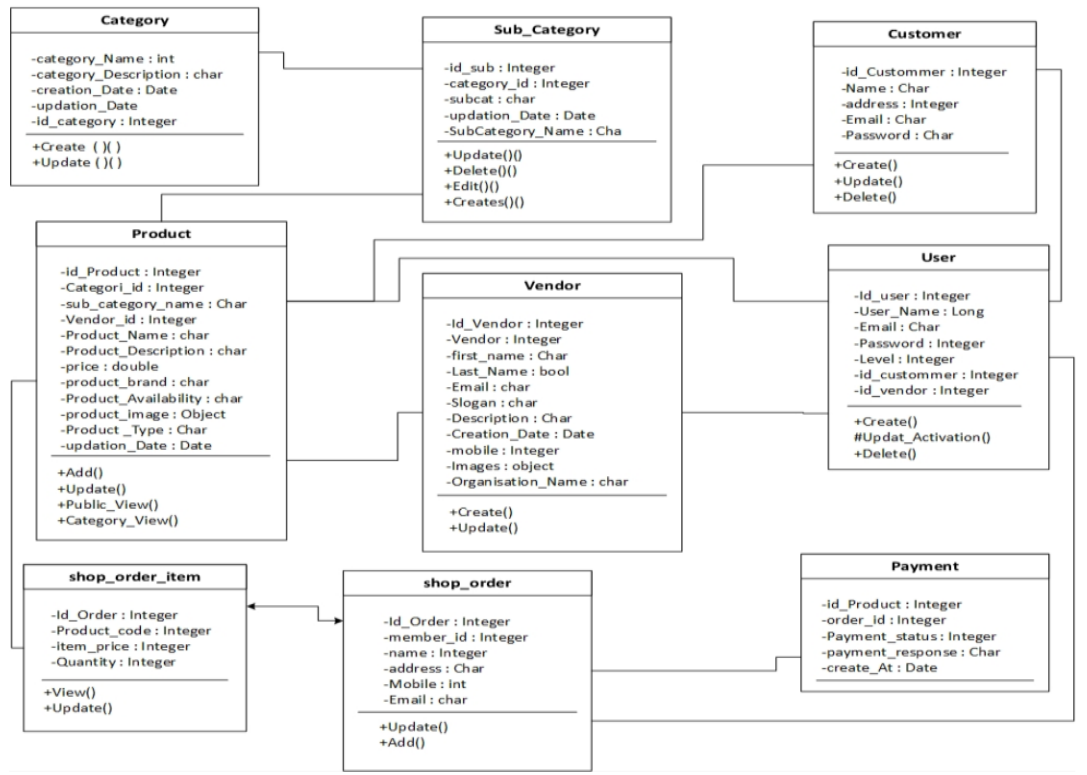

Gambar 5. Skema Perancangan Database Pasar Digital 


\subsection{Tampilan Sistem Pasar Digital Berbasis Multivendor}
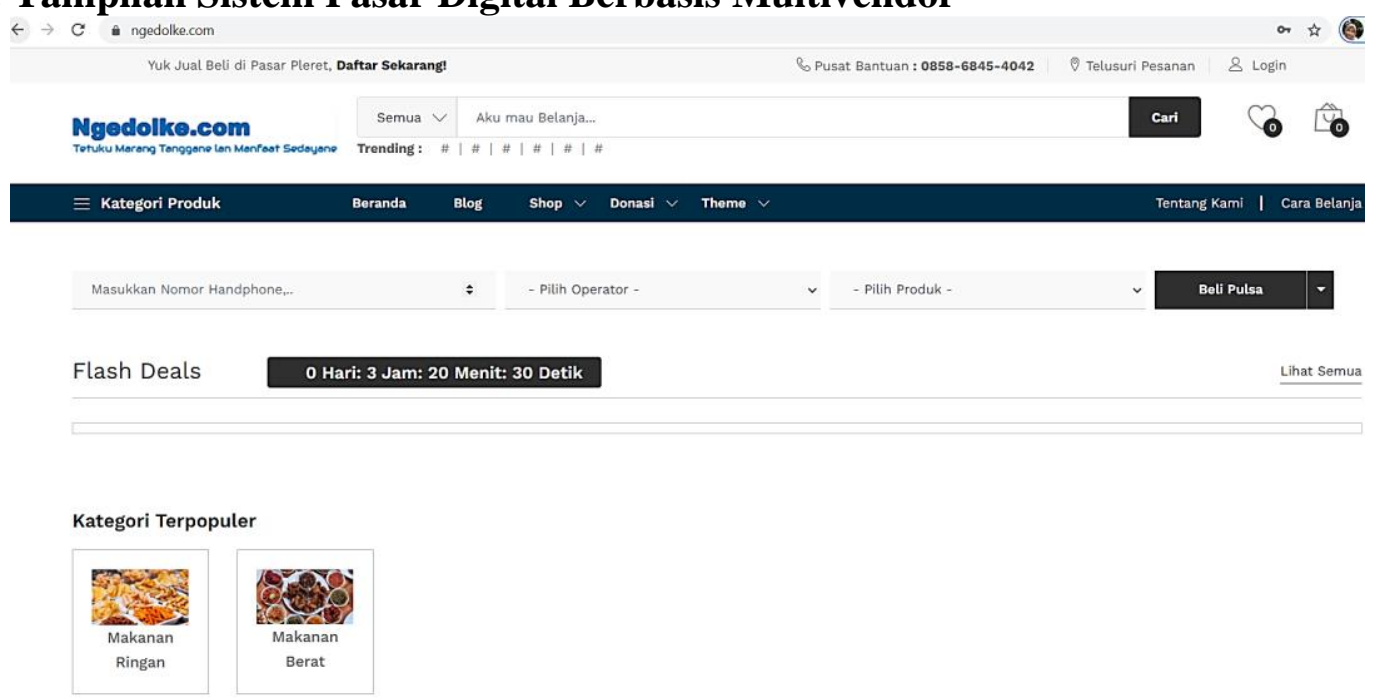

Gambar 6. Website ngedolke.com

Pada sistem pasar digital ngedolke.com, terdapat tampilan beranda (Gambar 6) yang berisikan tentang kategori-kategori produk dan akses untuk melakukan transaksi penjualan dan pembelian. Di bagian bawah halaman, footer menyertakan pedoman bagi pembeli dan pelapak tentang cara berbelanja dan berjualan, pembayaran dan keuntungan penjualan, jaminan keamanan dan indeks merek, serta jasa pengadaan dan direktori pelapak.

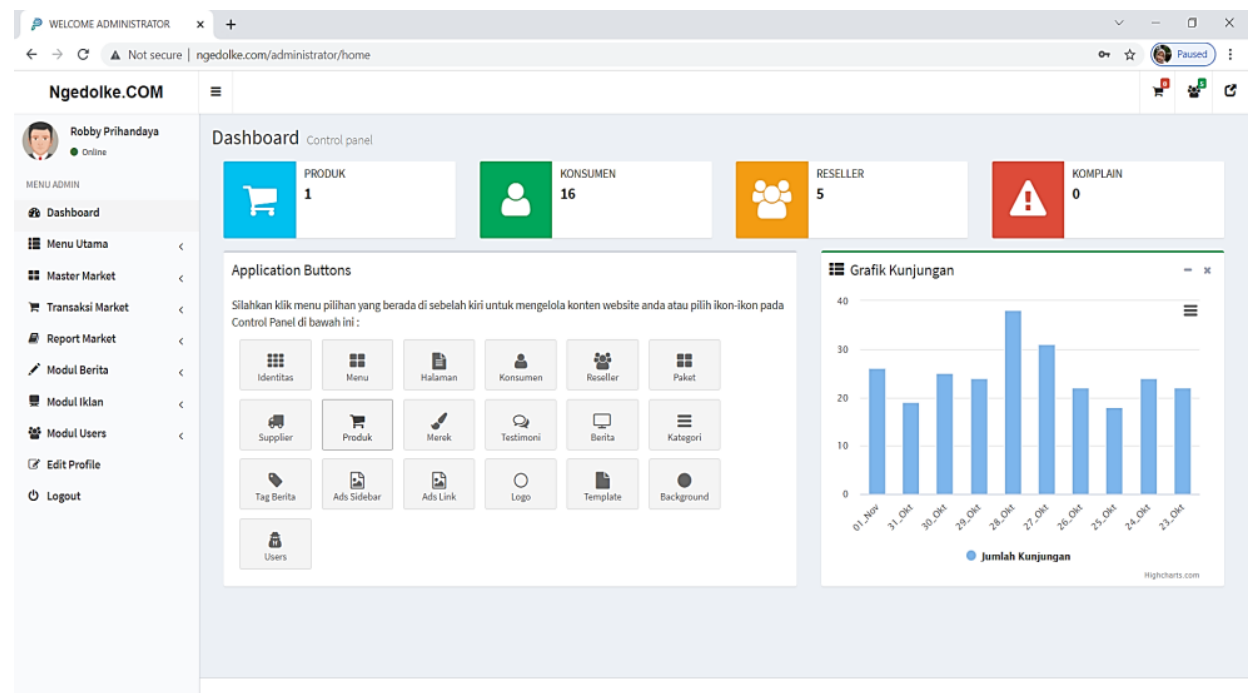

Gambar 7. Bentuk Tampilan Web Admin 
Setelah mengisi username dan password, layar akan menampilkan Menu Admin seperti Gambar 7. Pada menu ini terdapat beberapa menu admin diantaranya Dashboard, Menu Utama, Master Market, Transaksi Market, Report Market, Modul Berita, Modul Iklan, Modul Users, Edit Profile dan Logout.

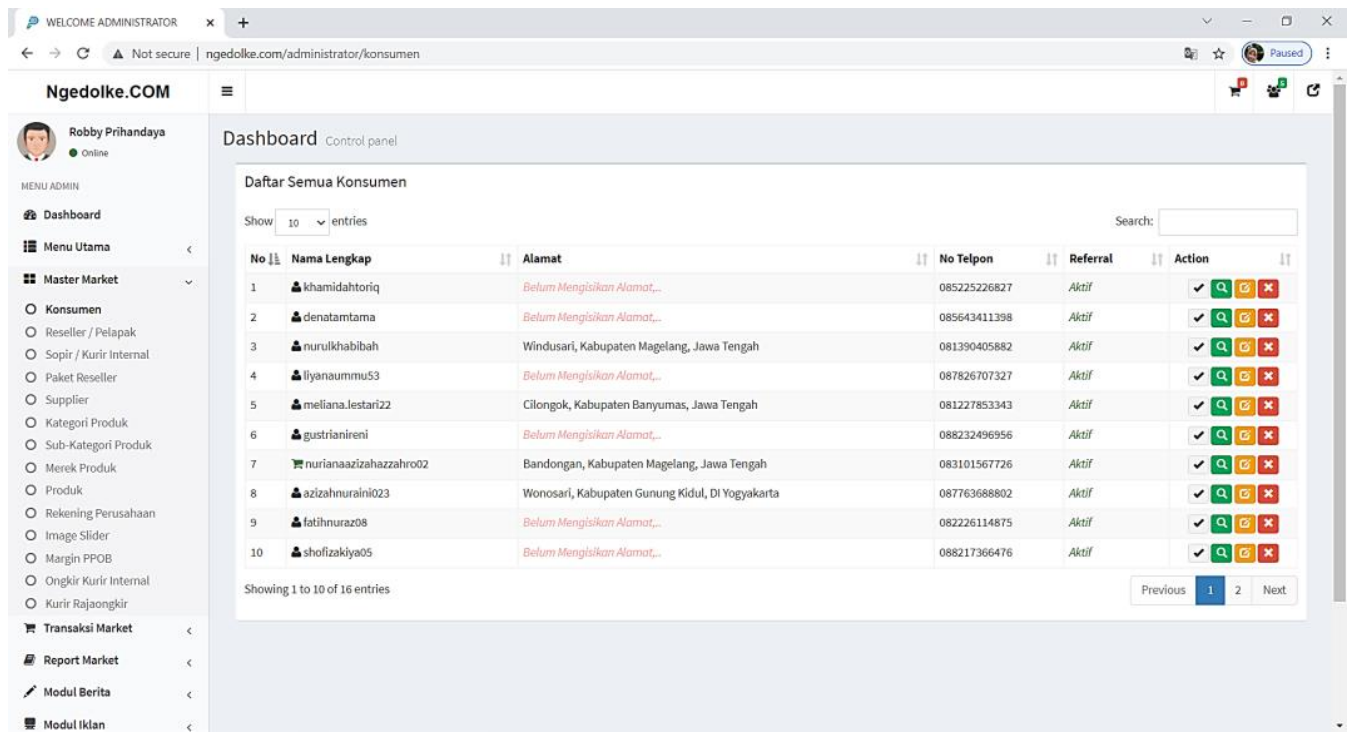

Gambar 8. Bentuk Tampilan Konsumen

Pada Gambar 8 menampilkan daftar konsumen yang telah melakukan transaksi pembelian di ngedolke.com. selain itu terdapat pula history belanja dan history transaksi pembelian.

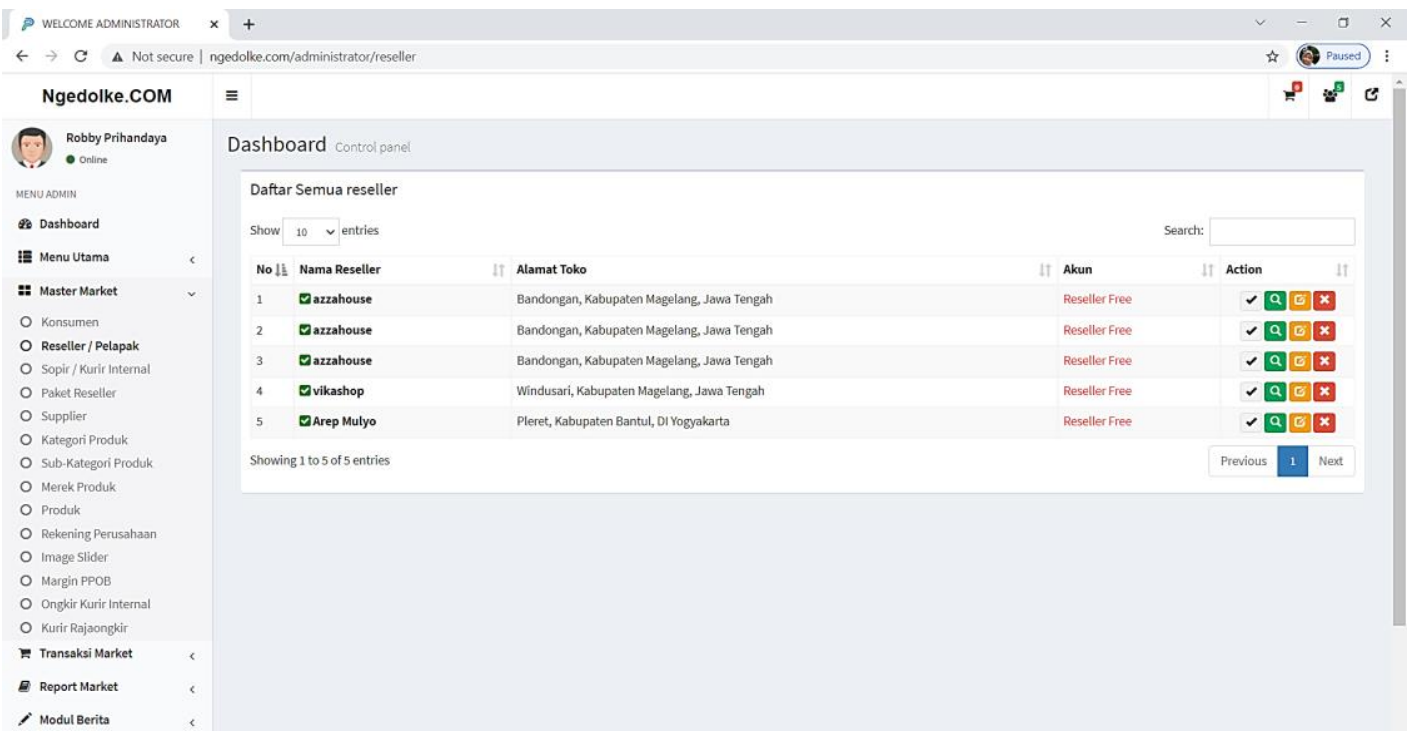

Gambar 9. Bentuk Tampilan Daftar Vendor

Pada Gambar 9 menampilkan daftar vendor yang bergabung dengan ngedolke.com. Baik sebagai reseller, maupun supplier. Untuk membuat daftar produk yang akan dijual, pengguna 
harus mengunggah foto barang tersebut dan memasukkan nama, deskripsi, kategori produk, harga, dan stok.

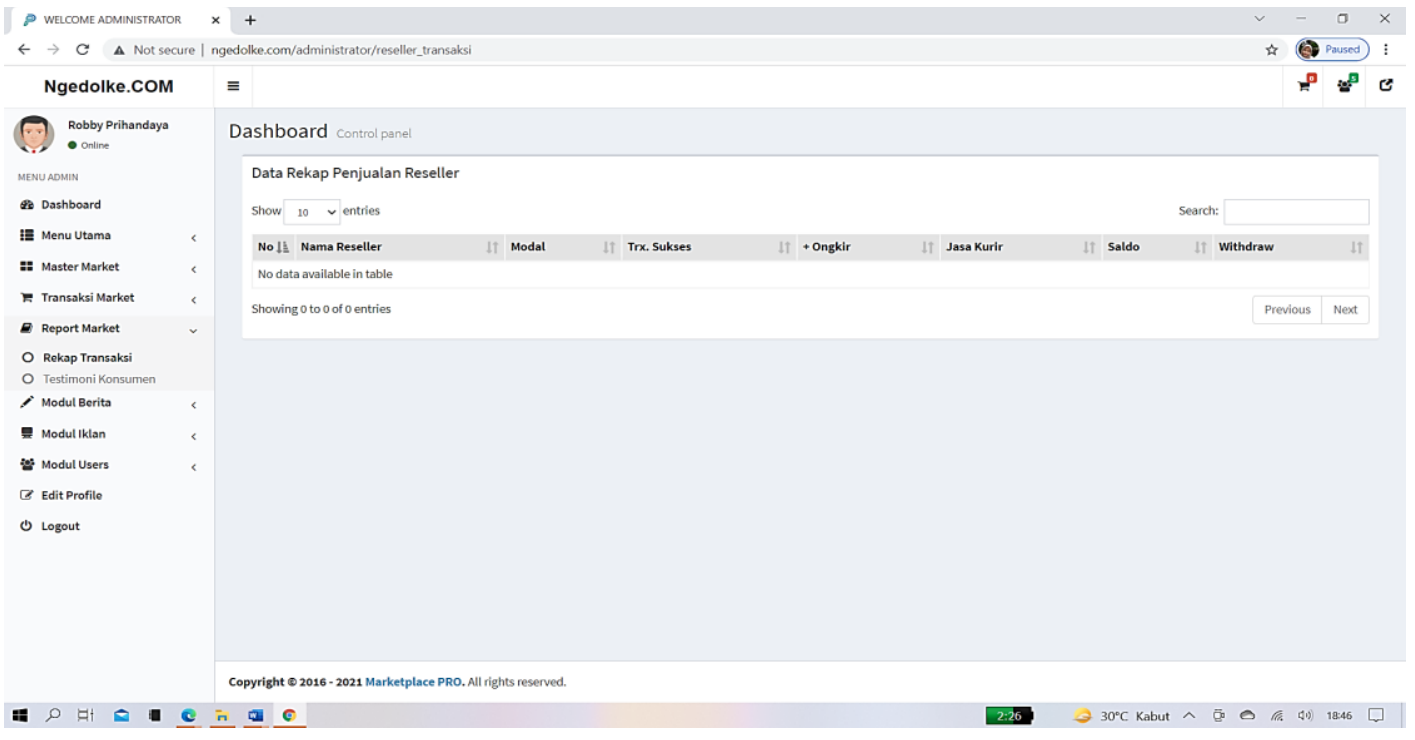

Gambar 10. Bentuk Tampilan Report Market

Pada gambar 10, menampilkan rekap transaksi dan testimoni konsumen. Rekap penjualan menyajikan laporan transaksi keuangan masing-masing vendor dan dapat mengunduh laporan akuntansinya.

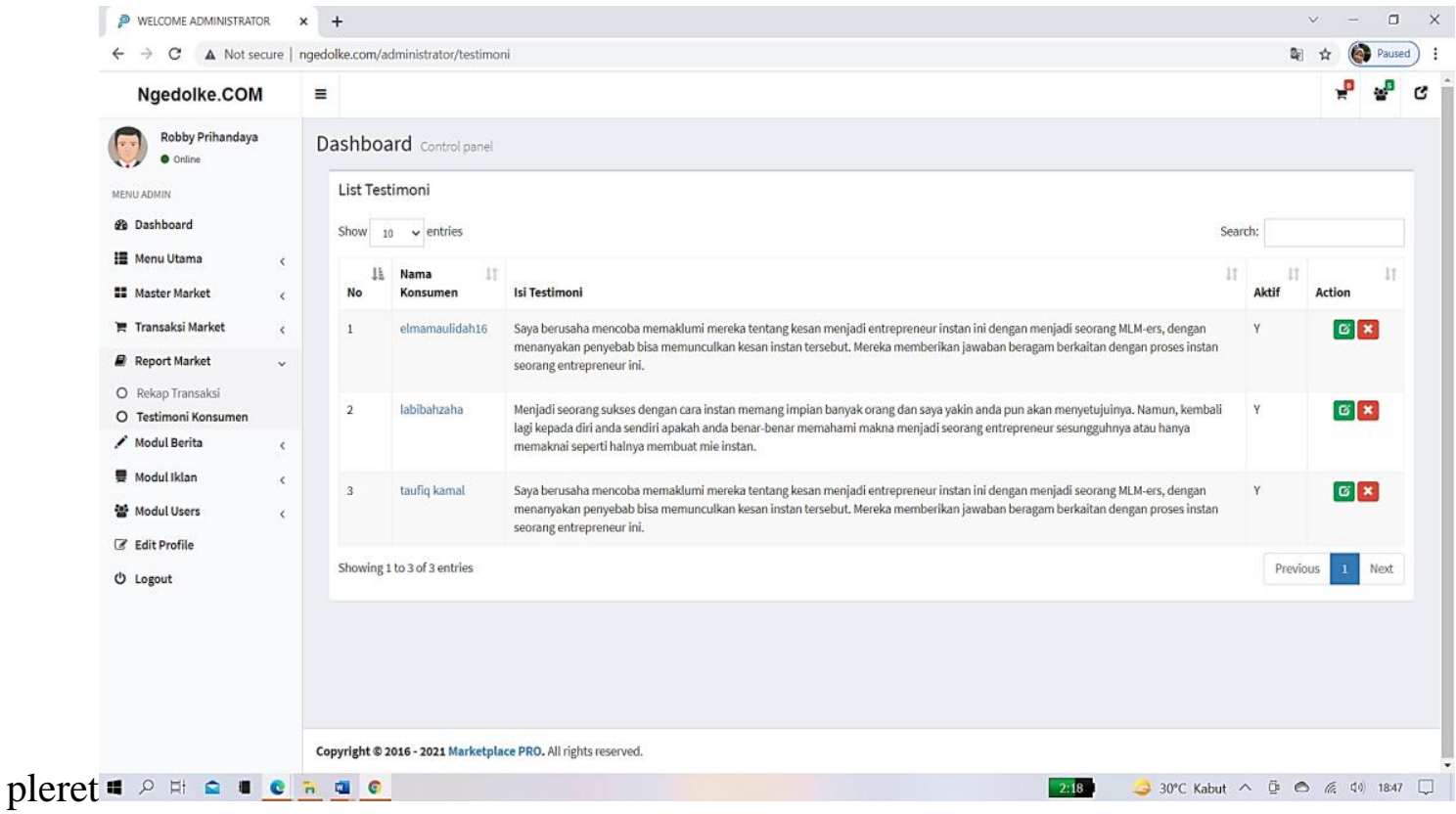

Gambar 11. Bentuk Tampilan Testimoni

ngedolke.com juga menyajikan tampilan testimoni dari konsumen seperti pada gambar 11 . Testimoni ini bertujuan sebagai masukan atau penilaian dari hasil transaksi jual beli. 


\section{Kesimpulan dan Saran}

Dari hasil implementasi dan pengujian sistem, maka dapat ditarik beberapa kesimpulan diantaranya dengan adanya teknologi e-commerce ngedolke.com dapat memudahkan transaksi jual beli dan menyediakan bermacam-macam produk dari berbagai vendor baik menggunakan web maupun mobile apps, sehingga membantu UMKM untuk memasarkan produknya agar dapat meningkatkan omset penjualan. Selain itu, E-commerce ngedolke.com memiliki pengawasan di bawah pemerintah desa Pleret yang akan memantau berjalannya sistem agar efektif dan efisien.

Bagi penelitian selanjutnya, sistem ini dapat dikembangkan dengan menambahkan fitur pesan antar atau Cash On Delivery (COD). Selain itu, aplikasi ini dapat dikembangkan dengan berbasis Android maupun IOS.

\section{Daftar Pustaka}

[1] R. Arezki et al., "Middle East and North Africa Economic Monitor, October 2018: A New Economy in Middle East and North Africa," Middle East North Africa Econ. Monit. Oct. 2018 A New Econ. Middle East North Africa, no. October, 2018, doi: 10.1596/9781-4648-1367-2.

[2] V. Zwass, "Electronic commerce and organizational innovation: Aspects and opportunities," Int. J. Electron. Commer., vol. 7, no. 3, pp. 7-37, 2003, doi: 10.1080/10864415.2003.11044273.

[3] Y. Lin, "A study on the relationship between project management competency, job performance and job motivation in e-commerce industry," Meas. Bus. Excell., vol. 25, no. 1, pp. 24-57, 2021, doi: 10.1108/MBE-10-2020-0144.

[4] D. Achjari, "Potensi Manfaat Dan Problem Di E-Commerce," J. Ekon. dan Bisnis Indones., vol. 15, no. 3, pp. 388-395, 2000, [Online]. Available: http://www.amazon.com.

[5] A. Khatibi, V. Thyagarajan, and A. Seetharaman, "E-commerce in Malaysia: Perceived benefits and barriers," Vikalpa, vol. 28, no. 3, pp. 77-82, 2003, doi: 10.1177/0256090920030307.

[6] J. M. Müller, "Antecedents to digital platform usage in Industry 4.0 by established manufacturers," Sustain., vol. 11, no. 4, 2019, doi: 10.3390/su11041121.

[7] F. Han and B. Li, "Exploring the effect of an enhanced e-commerce institutional mechanism on online shopping intention in the context of e-commerce poverty alleviation," Inf. Technol. People, vol. 34, no. 1, pp. 93-122, 2021, doi: 10.1108/ITP-122018-0568.

[8] W. Febriantoro, "Kajian Dan Strategi Pendukung Perkembangan E-Commerce Bagi Umkm Di Indonesia," J. MANAJERIAL, vol. 17, no. 2, p. 184, 2018, doi: 10.17509/manajerial.v17i2.10441.

[9] A. Y. Apriadi, D., \& Saputra, "E-Commerce Berbasis Marketplace Dalam Upaya Mempersingkat Distribusi Penjualan Hasil Pertanian," Rekayasa Sist. dan Teknol. Inf., vol. 1, no. 1, pp. 19-25, 2017. 
[10] A. Susanty, A. Handoko, and N. B. Puspitasari, "Push-pull-mooring framework for ecommerce adoption in small and medium enterprises," J. Enterp. Inf. Manag., vol. 33, no. 2, pp. 381-406, 2020, doi: 10.1108/JEIM-08-2019-0227.

[11] J. Samodra, A. S. Pahlevi, and Y. A. L. Hermanto, "Pasar Desa Digital Berbasis Web Sebagai Media Promosi Bagi Umkm," J. KARINOV, vol. 2, no. 3, p. 177, 2019, doi: 10.17977/um045v2i3p177-180.

[12] D. S. Putra and A. Djazuli, "Pengaruh Strategi Resource-Based terhadap Keunggulan Bersaing yang Dimediasi oleh Orientasi Kewirausahaan ( Studi pada Usaha Kecil Menengah Sasirangan Kota Banjarmasin )," J. Apl. Manaj., vol. 11, no. September, pp. 392-398, 2013, [Online]. Available: https://jurnaljam.ub.ac.id/index.php/jam/article/view/122.

[13] M. Iffah, F. R. Sutikno, and N. Sari, "Pengaruh Toko Modern terhadap Toko Usaha Kecil Skala Lingkungan (Studi Kasus : Minimarket Kecamatan Blimbing, Kota Malang), J. Tata Kota dan Drh., vol. 3, pp. 55-64, 2011.

[14] W. laura Hardilawati, "Strategi Bertahan UMKM di Tengah Pandemi Covid-19," J. Akunt. dan Ekon., vol. 10, no. 1, pp. 89-98, 2020, doi: 10.37859/jae.v10i1.1934.

[15] D. Wibisono, "Marketing Strategy of Madilog Coffee Shop using Influencers through Instagram Social Media," J. Ad'ministrare, vol. 7, no. 1, p. 191, 2020, doi: 10.26858/ja.v7i1.14664.

[16] World Development Group, World development report 2016: digital dividends. World Bank Publications, 2016.

[17] N. Martins, D. Brandão, H. Alvelos, and S. Silva, "E-marketplace as a tool for the revitalization of portuguese craft industry: The design process in the development of an online platform," Futur. Internet, vol. 12, no. 11, pp. 1-23, 2020, doi: 10.3390/fi12110195.

[18] M. Hincapie, C. Diaz, M. Zapata, and C. Mesias, "Methodological framework for the design and development of applications for reactivation of cultural heritage: Case study cisneros marketplace at Medellin, Colombia," J. Comput. Cult. Herit., vol. 9, no. 2, 2016, doi: $10.1145 / 2827856$.

[19] Y. Hendriana, "Modelling And Design E-Commerce SMI Sector Using Zachman Framework," Int. J. Comput. Sci. Inf. Secur., vol. 13, no. 8, pp. 9-14, 2015.

[20] Y. Hendriana, A. Pranolo, S. Sulaiman, and L. H. Fong, "Generic shopping mall directory mobile application," Proc. - 2015 Int. Conf. Sci. Inf. Technol. Big Data Spectr. Futur. Inf. Econ. ICSITech 2015, pp. 363-368, 2016, doi: 10.1109/ICSITech.2015.7407833. 